\title{
Patient Preferences for Pharmacological Diabetes Treatment Among People with Diabetes in Spain: A Discrete Choice Experiment
}

\author{
Fernando Gómez-Peralta · María Mareque (D) · Álvaro Muñoz • \\ Mercedes Maderuelo · Miguel Ángel Casado
}

Received: September 21, 2021 / Accepted: October 28, 2021 / Published online: November 18, 2021

(C) The Author(s) 2021

\begin{abstract}
Introduction: The aim of the project was to describe the preferences related to the medication attributes of people with diabetes mellitus (DM) treated in Spain.

Methods: The project was carried out in four different phases. In phase A, a Steering Committee defined and selected a total of 18 attributes for treating DM and grouped them into four categories: health outcomes, adverse events, treatment characteristics and cost of treatment. In phase B, a questionnaire according to a discrete choice experiment (DCE) methodology was developed. In phase $C$, the online DCE survey was sent to members of associations of people with DM from the Spanish Diabetes Federation (FEDE). Finally, in phase
\end{abstract}

Supplementary Information The online version contains supplementary material available at https:// doi.org/10.1007/s13300-021-01178-9.

F. Gómez-Peralta

Unidad de Endocrinología y Nutrición, Hospital

General de Segovia, Segovia, Spain

M. Mareque $(\bowtie) \cdot$ Á. Muñoz · M. Á. Casado Pharmacoeconomics \& Outcomes Research Iberia (PORIB), Madrid, Spain

e-mail: mmareque@porib.com

M. Maderuelo

Federación Española de Diabetes, Madrid, Spain
$\mathrm{D}$, the results were discussed in a deliberative process.

Results: Of the 238 participants who completed the questionnaire (May-September 2020), 231 were included (mean age, 58 years; males, 62\%). The DCE results showed that the best-valued category was health outcomes (39.67\%), followed by adverse events $(26.85 \%)$, treatment characteristics $(21.70 \%)$ and treatment costs $(11.77 \%)$. Ten of 18 attributes had a significant effect on participants' choice $(p<0.05)$ and the highest relative importance value: blood pressure reduction (12.82\%), hypoglycaemia (12.77\%), $\mathrm{HbA}_{1 \mathrm{c}}$ level reduction $(8.54 \%)$, cost of the medication $(8.13 \%)$, needle/tablet size $(7.20 \%)$, weight change $(6.72 \%)$, risk of genitourinary infections $(6.36 \%)$, gastrointestinal problems $(5.82 \%)$, improved kidney function $(5.53 \%)$ and administration route (5.41\%).

Conclusions: People with DM prefer a treatment that generates benefits in measurable health effects (reducing blood pressure and $\mathrm{HbA}_{1 \mathrm{c}}$ level, while not risking hypoglycaemia) and a convenient route of administration. Considering the preferences of people with DM could generate better clinical results and therapeutic adherence, reducing morbidity, mortality and disease burden.

Keywords: Diabetes mellitus; Discrete choice experiment; Patient preference; Spain 


\section{Key Summary Points}

Using a discrete choice experiment, we describe the medication attribute preferences of people with diabetes mellitus (DM) treated in Spain

People with DM reported that they prefer a treatment that generates benefits in those parameters with short-/medium-term consequences, such as blood pressure reduction without risk of hypoglycaemia and reduction of $\mathrm{HbA}_{1 \mathrm{c}}$ level

Further research is needed to address whether considering patients' preferences has impact on the outcomes. Additionally, patients should be incorporated in the process of designing diabetes protocols and guidelines

\section{INTRODUCTION}

Diabetes mellitus (DM) is a group of diseases characterized by chronic hyperglycaemia due to insufficient production and/or a decreased action of insulin in its target organs, especially muscle and liver [1], affecting approximately 436 million adults worldwide [2]. The overall prevalence is estimated to be $8.1 \%$ in the adult population, increasing progressively with age to $23.1 \%$ in the 70-74-year age group [2]. According to the Di@bet.es study, the prevalence of this disease in adults in Spain is $13.8 \%$, including $40.0 \%$ of undiagnosed cases [3].

DM is one of the leading causes of morbidity and premature mortality in the adult population, placing a high burden on patients and society $[4,5]$. Therefore, DM is one of the most relevant chronic diseases, with a major socioeconomic impact, not only due to its high prevalence but also to the associated chronic complications. These complications are associated with a reduction in the quality of life of patients as they lead to depression, anxiety, 
that this approach leads to increased satisfaction, better adherence and improved health outcomes [26-28]. Knowledge of patients' preferences about treatment attributes can guide patient-centred research and the development of new treatments with more favourable profiles. Therefore, it is important to know patients' preferences especially in chronic diseases such as diabetes, as treatment for this disease requires significant patient's involvement in their care and self-management to achieve glycaemic control [29]. In this context, the objective of the present project was to determine the preferences of people with DM for different attributes of medications for treating this disease in Spain, using a DCE.

\section{METHODS}

The project was carried out in four different phases: (a) definition and selection of attributes; (b) development of the questionnaire according to DCE methodology; (c) DCE survey of people with DM; (d) analysis and contextualization of the results (Fig. 1).

\section{A) Definition and Selection of Criteria}

First, a literature review was conducted in the MEDLINE database through the PubMed search engine to identify publications on drug treatment preferences in patients with DM to identify the potential attributes to include in the preference survey. The search strategy was designed using a combination of the following search terms related to the disease ("diabetes mellitus" and "diabetes mellitus type 2") and terms related to the preference assessment methodology ("discrete choice" and "discrete choice experiment") (Table 1. Supplementary Material). A total of 61 potentially relevant publications were identified in the initial search, 37 of which were excluded, after a full text reading, as they did not meet the inclusion criteria (preference assessment method related to pharmacological treatment for DM). Finally, 24 publications were selected (Table 2. Supplementary Material) for the extraction of attributes and/or levels (Fig. 1. Supplementary Material), from which a list of possible attributes to be included in the preference survey was obtained.

A Steering Committee formed by a representative of the Spanish Diabetes Federation (FEDE) and an expert appointed by the SED collaborated with three experts in health outcomes research to validate and agree on the attributes that are potentially relevant to the assessment of possible treatment for DM, grouping them into several decision categories. Finally, 18 attributes were selected and grouped into four categories: treatment characteristics, health outcomes, adverse events and treatment costs. The attributes and levels finally selected are shown in Table 3. Supplementary Material.

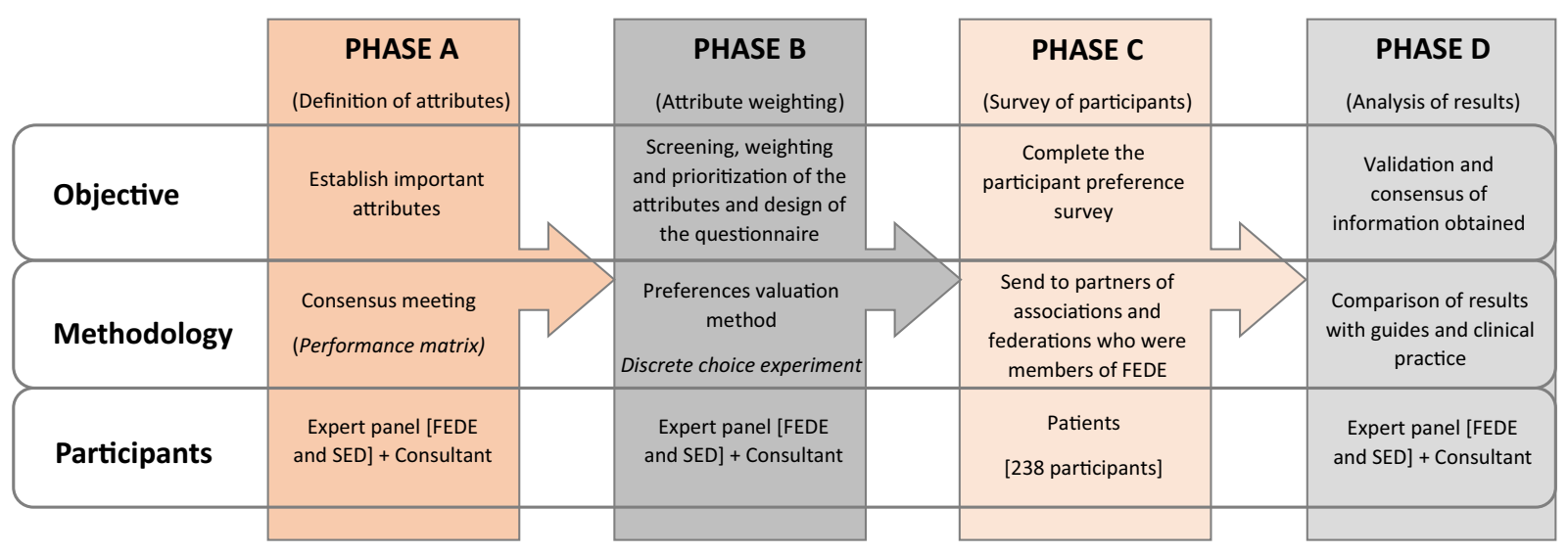

FEDE: Spanish Diabetes Federation; SED: SpanishDiabetes Society

Fig. 1 Project phases 


\section{B) Development of the Questionnaire According to DCE Methodology}

An electronic questionnaire was developed in Google Forms to conduct a DCE following to international good practice recommendations [30, 31]. DCE is a robust approach to examining patient preferences that is increasingly used in healthcare research to help make approval decisions based on patient preferences. In this method, participants are presented with several choice sets, each of which presents two hypothetical scenarios from which they are asked to choose one of them. A series of attributes describe each scenario, and each attribute has one of the levels describing the ranges in which the attributes vary. The DCE repeatedly presents pairs of scenarios in alternating order to prevent participants from considering all attributes simultaneously and making their choice based on the trade-offs between all attributes [22, 24]. This questionnaire consisted of two sections:

(1) Questions related to sociodemographic and clinical characteristics

The following variables were included: age (years), sex, weight $(\mathrm{kg})$, height $(\mathrm{m})$, glycated haemoglobin $\left(\mathrm{HbA}_{1 \mathrm{c}}\right)$ level (last measurement), year of disease diagnosis, and current treatment. Body mass index (BMI) was calculated using the formula BMI $=$ weight $(\mathrm{kg}) /$ height $(\mathrm{m})^{2}$.

(2) Questions related to hypothetical treatment preferences according to DCE methodology

To establish the statistical significance of attributes and levels relevant among the patient preferences, the minimum number of pairs of scenarios that needed to be included in the questionnaire was calculated through an orthogonal design using the "Support.Ces" package. A total of 36 questions were generated, consisting of a unique combination of attributes and levels, from the list previously selected in phase A, describing the characteristics of a hypothetical drug for the treatment of DM in Spain. For each question, participants were asked to select which of the two hypothetical treatments (treatment A or treatment B) proposed was more appropriate according to their preferences. An example of a question from the
DCE preference assessment is shown in Fig. 2 in the Supplementary Material.

\section{C) DCE Survey of People with DM for Screening and Weighting of the Criteria}

Participants were recruited via e-mail by FEDE for a time frame of 4 months (May-September 2020). FEDE is a representative body of people with DM in Spain, which includes about 150 associations of people with DM distributed throughout the country. To be eligible for the project, participants had to meet the following main criteria: 18 years of age or older; diagnosed with DM; a resident of Spain; and, members of an association of people with DM. FEDE sent, by e-mail, the invitation to participate in the project. This e-mail included the instructions for the questionnaire, indicating that completion of the questionnaire was completely voluntary. In case of response, all data would be anonymised and the participants accepted the use of the aggregated data for subsequent scientific diffusion. FEDE guaranteed anonymity and voluntary participation while preserving the confidentiality of the participants based on the Helsinki Declaration. No third parties had access to participants' data. For this, the approval of an ethics committee was not considered relevant.

Prior to initiating the main data collection, the attributes and levels were tested in a pilot study with FEDE associate members with a diagnosis of DM to adapt the survey questions and make the survey as practical and simple as possible (these responses were not considered in the analysis). Based on the feedback received, minor adjustments were made to clarify the instructions and the wording of the attributes and levels. Subsequently, once the questions had been adapted, FEDE sent the online questionnaire to members of associations of people with DM. All responses were anonymous and no identifying personal information was collected. 


\section{D) Statistical Analysis}

\section{and Contextualization of the Results}

All data were validated and checked for consistency and errors before performing statistical analysis. Any participants who responded incorrectly to the fixed choice question were excluded from the analysis. In addition, missing values were not considered in the analysis.

All statistical analyses were performed using $\mathrm{R}$ software (version 3.2.3, $\mathrm{R}$ Foundation for Statistical Computing, Vienna, Austria) [32].

\section{Descriptive Analysis}

To determine the sociodemographic and clinical characteristics of the participants, a descriptive analysis was carried out. For quantitative variables (age, weight, height, level of $\mathrm{HbA}_{1 \mathrm{c}}$ and time since diagnosis), the mean and standard deviation (SD) and the maximum and minimum values were calculated; for qualitative variables (sex and current treatment), absolute and relative frequencies were calculated as percentages.

\section{Discrete Choice Experiment}

To analyse the survey responses and determine the relevance of the attributes and levels according to the participants' stated preferences, according to Lancsar et al. [24], a multinomial logit model with an error value of $p=0.05$ was fitted to assess the significance of the contrasts. In this model, a $\beta$ coefficient was obtained for each attribute, indicating the direction and weight of the attribute in the global preferences of the participants. From this $\beta$ coefficient and its standard error (SE), a normal $z$-distribution was obtained, which allowed us to calculate whether a certain attribute had a statistically significant influence on the preferences of the participants. From the $\beta$ coefficient, the odds ratio (OR) was calculated, indicating the importance of the presence of an attribute compared to its absence, such that a value significantly greater than $1(p<0.05)$ indicated importance to participants. Consequently, an inverse of the OR that was significantly greater than 1 indicated how preferable the absence of that attribute was to the participant. With the results of this model, we determined the intensity of each criterion in the preferences $\left(V_{\mathrm{D}}\right)$ and the relative importance $\left(W_{\mathrm{D}}\right)$ of each of their attributes, such that a higher $W_{\mathrm{D}}$ meant a greater importance of this attribute than the rest of the attributes in the preferences of the participants. Considering $n$ evaluated criteria, $V_{\mathrm{D}}$ and $W_{\mathrm{D}}$ were calculated using the following equation:

$$
V_{\mathrm{D}}=\left|\operatorname{Coef}_{\mathrm{D}}\right| / \mathrm{SE}_{\mathrm{D}} W_{\mathrm{D}}=\frac{V_{\mathrm{D}}}{\sum_{i=1}^{n} V_{\mathrm{D} i}} \times 100
$$

Coef is the $\beta$ coefficient; SE is the standard error.

\section{Contextualization of the Results}

Again, the Steering Committee evaluated the results of the questionnaire, and their statistical analysis and compared them with previously selected literature and international clinical recommendations.

\section{RESULTS}

A total of 238 participants completed the questionnaire. Seven were excluded from the analysis [two participants because they did not fit with the national scope of the project and five because their answers were deemed inconsistent (two for giving all the same responses to the DCE questions and three for giving all the same responses except for one)]. Therefore, the responses of 231 participants were considered for the data analysis (Fig. 3. Supplementary Material).

\section{Sociodemographic and Clinical Characteristics}

The sociodemographic and clinical characteristics of the participants analysed are described in Table 1. The mean (SD) age was 58.06 (10.70) years, and $61.90 \%$ of participants were male. The mean (SD) $\mathrm{HbA}_{1 \mathrm{c}}$ level of the participants was $7.00(0.71) \%$, and the mean (SD) BMI was $25.54(3.88) \mathrm{kg} / \mathrm{m}^{2}$. The mean (SD) time since diagnosis of the disease was 16.61 (11.47) years. 
Table 1 Sociodemographic and clinical characteristics

\begin{tabular}{|c|c|}
\hline Characteristic & Total population $(N=231)$ \\
\hline \multicolumn{2}{|l|}{ Age $^{a}$, years } \\
\hline Mean (SD) & $58.06(10.70)$ \\
\hline \multicolumn{2}{|l|}{ Sex, $n(\%)$} \\
\hline Male & $143(61.90)$ \\
\hline Female & $88(38.10)$ \\
\hline \multicolumn{2}{|l|}{ Weight $^{a}, \mathbf{k g}$} \\
\hline Mean (SD) & $73.39(13.09)$ \\
\hline \multicolumn{2}{|l|}{ Height $^{a}$, m } \\
\hline Mean (SD) & $1.69(0.09)$ \\
\hline \multicolumn{2}{|l|}{ Body mass index ${ }^{b}, \mathrm{~kg} / \mathrm{m}^{2}$} \\
\hline Mean (SD) & $25.54(3.88)$ \\
\hline \multicolumn{2}{|l|}{ Level of $\mathrm{HbA}_{1 \mathrm{c}}{ }^{\mathrm{d}}$, \% } \\
\hline Mean (SD) & $7.00(0.71)$ \\
\hline \multicolumn{2}{|l|}{ Time since diagnosis ${ }^{c}$, years } \\
\hline Mean $(S D)$ & $16.61(11.47)$ \\
\hline \multicolumn{2}{|l|}{ Current treatment ${ }^{\mathrm{d}}, \mathbf{n}(\%)$} \\
\hline Diet and exercise & $3(1.30)$ \\
\hline OADs/GLP-1 & $84(36.36)$ \\
\hline Basal insulin (Basal insulin \pm OADs \pm GLP-1) & $55(23.81)$ \\
\hline Insulin, complex regimens ${ }^{\mathrm{e}}$ & $76(32.90)$ \\
\hline
\end{tabular}

$S D$ standard deviation, $O A D s$ oral antidiabetic drugs, GLP-1 glucagon-like peptide-1

${ }^{\mathrm{a}} 1$ missing value

${ }^{\mathrm{b}} 2$ missing values

${ }^{\mathrm{c}} 10$ missing values

${ }^{\mathrm{d}} 18$ missing values

${ }^{\mathrm{e}}$ Complex insulin regimens: basal insulin + rapid-acting insulin, OADs + rapid-acting insulin

Regarding treatments, $36.36 \%$ of the participants reported being treated with oral antidiabetic drugs (OADs) or glucagon-like peptide-1 (GLP-1) receptor agonists (as monotherapy, double therapy or triple therapy), 23.81\% with basal insulin (basal insulin + OADs + GLP-1) and $32.90 \%$ with complex insulin regimens (basal insulin + rapid-acting insulin, OADs + rapid-acting insulin). In addition, three participants reported being on diet and exercise (Table 1).

\section{Preference Survey: Discrete Choice Experiment}

The most important category to people with DM was health outcomes (39.67\%), followed by adverse events (26.85\%) and treatment characteristics $(21.70 \%)$, with treatment costs $(11.77 \%)$ being the least important category (Fig. 2).

According to the multinomial logit model, 10 of 18 attributes had a significant effect on 


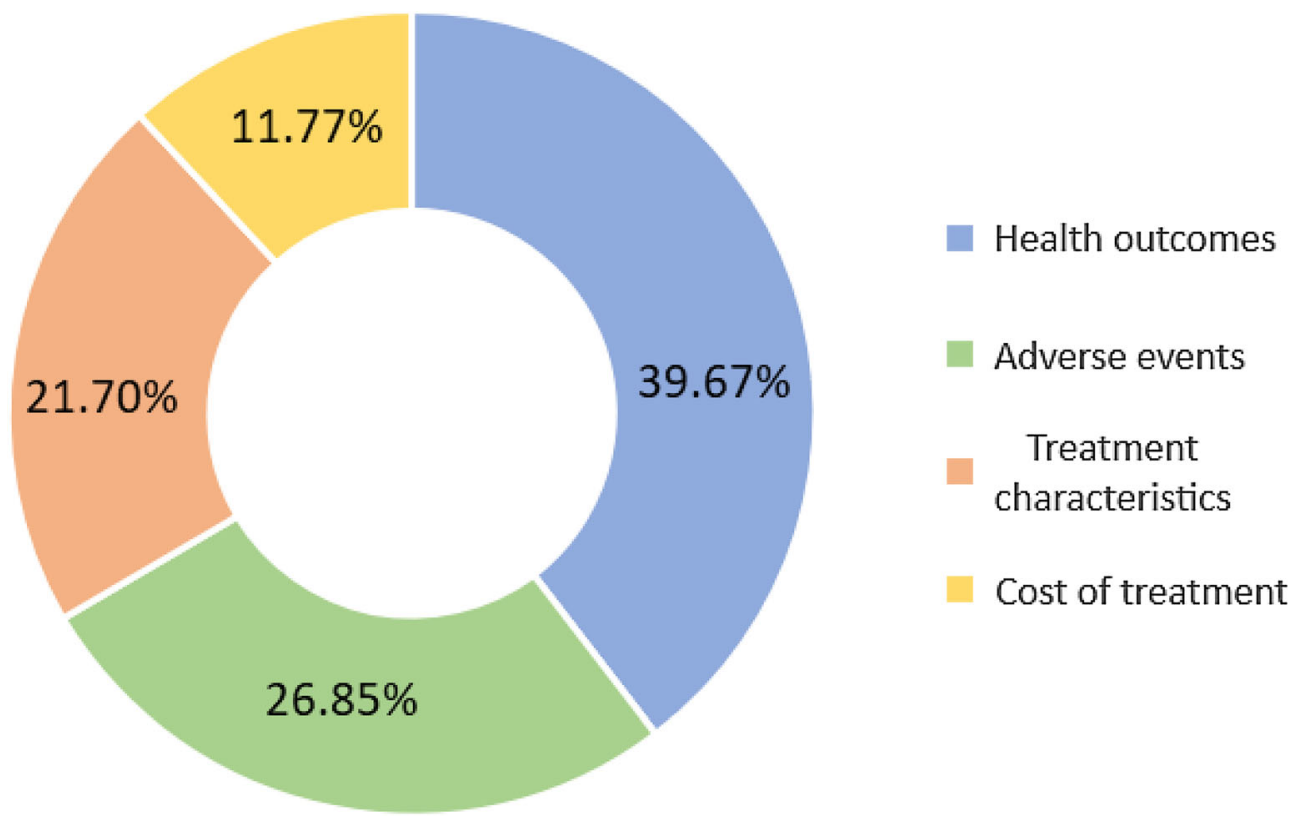

Fig. 2 Relative importance of attributes by category

participants' choice $(p<0.05)$ (Table 2). Blood pressure reduction, risk of hypoglycaemia, and $\mathrm{HbA}_{1 \mathrm{c}}$ level reduction were the attributes with the highest weight in participants' preferences with a relative importance of $12.82 \%, 12.77 \%$ and $8.54 \%$, respectively. All attributes in order of relative importance are shown in Table 2.

Figure 3 shows the relative importance of the individual attributes within each of the categories. In the health outcomes category, blood pressure reduction was the attribute with the greatest relative importance $(12.82 \%)$, followed by $\mathrm{HbA}_{1 \mathrm{c}}$ level reduction (8.54\%) and weight change $(6.72 \%)$. Regarding the category of adverse events, the possible presence of hypoglycaemia $(12.77 \%)$ and the risk of genitourinary infections $(6.36 \%)$ were the most relevant criteria. The most relevant and weighted attribute within the category including attributes associated with the treatment characteristics was the size of the needle/tablet (7.20\%). Administration route (5.41\%) was the following attribute with the highest relative importance in this category. Finally, medication cost to the NHS, regardless of patient contribution, was the attribute with the greatest relative importance $(8.13 \%)$ in the treatment costs category.
The coefficients obtained in the multinomial logit model are shown in Table 2. The sign of the $\beta$ coefficient was as expected for all attributes except the risk of suffering genitourinary infections. For the participants, a hypothetical treatment with blood pressure reduction, without risk of hypoglycaemia, with a reduction of more than $1.5 \%$ points in the $\mathrm{HbA}_{1 \mathrm{c}}$ level, at low cost to the NHS and oral administration in as small tablet as possible was preferred.

\section{DISCUSSION}

This project used the DCE methodology to assess the preferences of people with DM according to which attributes have greater importance when choosing pharmacological treatments to manage this disease. The results show that the improvement in health outcomes is the category that participants most value in a DM treatment, even given the possibility of suffering adverse events. This finding indicates a high degree of commitment to the goal treatment efficacy in the population analysed. These data are similar to those reported in several studies, where patients were willing to trade 
Table 2 Results of the discrete choice experiment

\begin{tabular}{|c|c|c|c|c|c|c|}
\hline Attribute & $\begin{array}{l}\beta \\
\text { (coefficient) }\end{array}$ & $\begin{array}{l}\text { Standard } \\
\text { error }\end{array}$ & $Z$-value & $p$-value & $\begin{array}{l}\text { Odds ratio } \\
\text { [inverse] }\end{array}$ & $\begin{array}{l}\text { Relative } \\
\text { importance } \\
(\%)\end{array}$ \\
\hline Blood pressure reduction & -0.185 & 0.031 & -5.946 & $<0.001$ & $0.831[1.20]$ & 12.82 \\
\hline Hypoglycaemia & -0.113 & 0.019 & -5.926 & $<0.001$ & $0.893[1.12]$ & 12.77 \\
\hline Reduction of $\mathrm{Hb} A_{1 c}$ level from baseline & 0.076 & 0.019 & 3.963 & $<0.001$ & $1.079[0.93]$ & 8.54 \\
\hline $\begin{array}{l}\text { Cost of the medication for the NHS } \\
\text { (regardless of patient contribution) }\end{array}$ & -0.072 & 0.019 & -3.770 & $<0.001$ & $0.931[1.07]$ & 8.13 \\
\hline Needle/tablet size & -0.104 & 0.031 & -3.340 & 0.001 & $0.901[1.11]$ & 7.20 \\
\hline Weight change from baseline & 0.059 & 0.019 & 3.117 & 0.002 & $1.061[0.94]$ & 6.72 \\
\hline Risk of genitourinary infections & -0.092 & 0.031 & -2.953 & 0.003 & $0.912[1.10]$ & 6.36 \\
\hline $\begin{array}{l}\text { Gastrointestinal problems (nausea, } \\
\text { vomiting, diarrboea) }\end{array}$ & -0.052 & 0.019 & -2.703 & 0.007 & $0.950[1.05]$ & 5.82 \\
\hline Improved kidney function & 0.049 & 0.019 & 2.568 & 0.010 & $1.05[0.95]$ & 5.53 \\
\hline Administration route & -0.048 & 0.019 & -2.512 & 0.012 & $0.953[1.05]$ & 5.41 \\
\hline Cardiovascular improvement & -0.061 & 0.031 & -1.950 & 0.051 & $0.941[1.06]$ & 4.20 \\
\hline Need for prior authorization & 0.053 & 0.031 & 1.688 & 0.091 & $1.054[0.95]$ & 3.64 \\
\hline Refrigeration of the medication & -0.050 & 0.031 & -1.598 & 0.110 & $0.951[1.05]$ & 3.44 \\
\hline Dosage & 0.022 & 0.019 & 1.163 & 0.245 & $1.022[0.98]$ & 2.51 \\
\hline Treatment comfort & -0.022 & 0.019 & -1.156 & 0.248 & $0.978[1.02]$ & 2.49 \\
\hline Injection site reaction & 0.028 & 0.031 & 0.884 & 0.377 & $1.028[0.97]$ & 1.90 \\
\hline $\begin{array}{l}\text { Reduction of chronic diabetic } \\
\text { complications }\end{array}$ & 0.027 & 0.031 & 0.863 & 0.388 & $1.027[0.97]$ & 1.86 \\
\hline Need for dosage adjustment & -0.006 & 0.019 & -0.303 & 0.762 & $0.994[1.01]$ & 0.65 \\
\hline
\end{tabular}

NHS National Health System

Attributes with $p<0.05$ are bol and italicized

higher adverse event risk for a more effective treatment [33, 34].

The highest weighted attributes to the patients were blood pressure reduction, not suffering hypoglycaemia and reducing $\mathrm{HbA}_{1 \mathrm{c}}$ level. It is noteworthy that blood pressure reduction was above exclusively glycaemic targets in DM, including hypoglycaemia. High blood pressure (HBP) is one of the main cardiovascular risk factors due to both its high prevalence and its impact [35, 36]. The prevalence of HBP in patients with DM is between 1.5 and 2 times higher compared to non-diabetic individuals with the same characteristics $[37,38]$. In addition, the coexistence of HBP and DM multiplies the risk of macrovascular disease (cardiac death, ischaemic heart disease, congestive heart failure, and cerebral and peripheral vascular disease) and microvascular disease (retinopathy, nephropathy and neuropathy) $[35,36]$. This result could support the progressive abandonment from a pure 


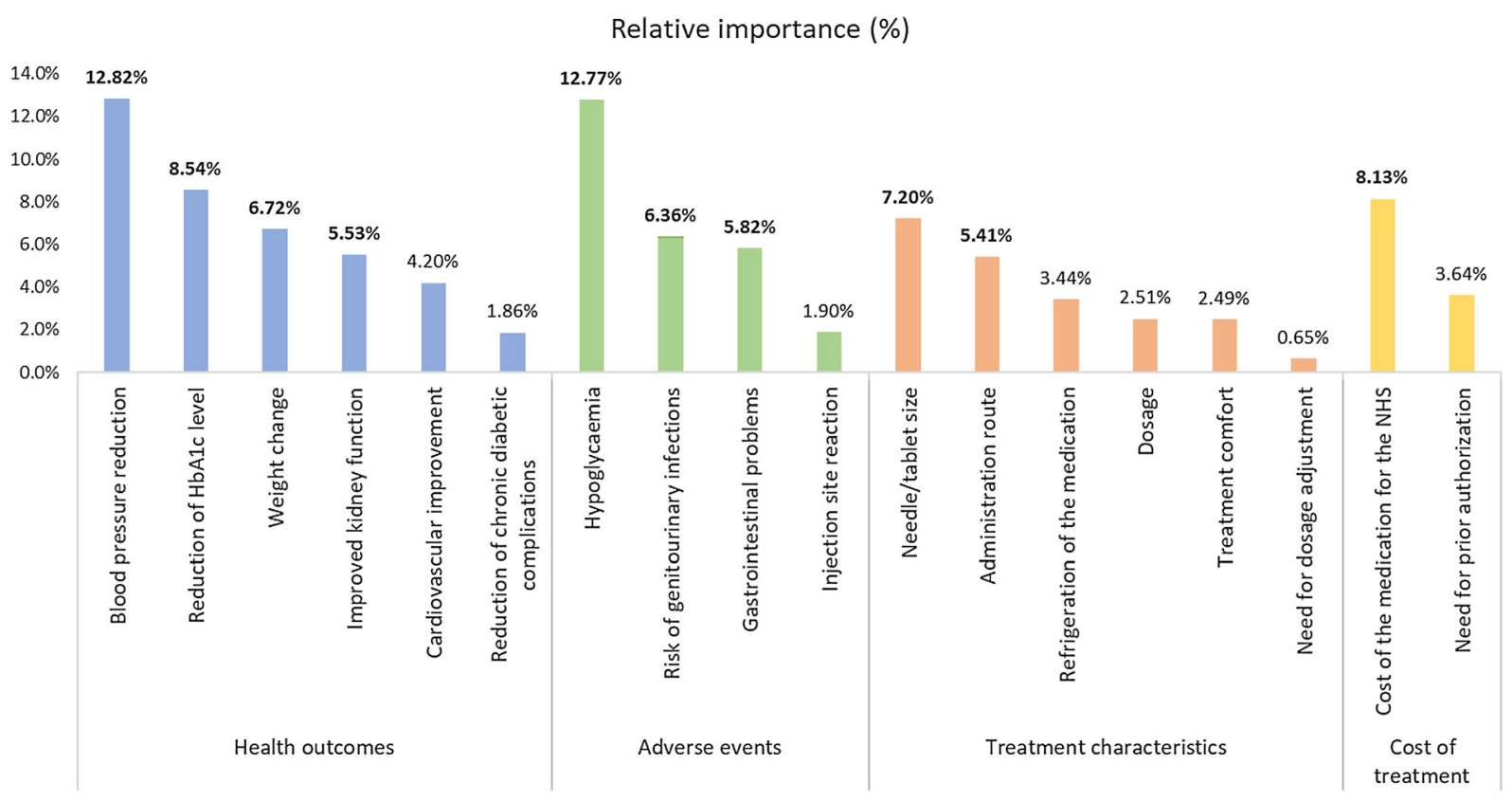

Fig. 3 Relative importance of individual attributes

glucocentric view of DM. Furthermore, it points-out to the open view that people with DM have of health, which is not always shared by healthcare professionals, particularly DM specialists [39].

In our analysis, hypoglycaemia obtained a relative importance with respect to the rest of the attributes, being in line with what has been reported by other studies, in which patients with type 2 diabetes mellitus (T2DM) indicated that the most important factor in both initiating and discontinuing treatment is the risk of suffering adverse effects [40].

As DM treatments are chronic, using formulations which are more convenient to administer and with lower requirements is important. Needle/tablet size and administration route were the most important attributes in the treatment characteristics category and had heavy weights in participants' preferences when choosing their hypothetical DM treatment. These results are also in line with the published literature, which considers that injectable treatment is usually an obstacle for patients, so it can delay treatment, leading to higher $\mathrm{HbA}_{1 \mathrm{c}}$ levels and an increased risk of DM-related complications [41-44].
Finally, despite the wide range of therapeutic options for the management of DM, reported adherence is low (20-50\%) [10-15]. The adherence rate drops faster after the first 6 months of treatment, being lower in patients with chronic diseases such as DM than in patients with acute diseases [45]. Therapeutic adherence is a fundamental part of successful treatment, leading to better clinical outcomes and a lower risk of complications, and consequently fewer hospitalizations, mortality and total healthcare costs $[19,46]$. Shared decision-making between patient and specialist can improve adherence and health outcomes and reduce healthcare costs [47]. Therefore, considering patients' preferences could help improve the adherence rate, reaching therapeutic targets and preventing complications.

To the authors' knowledge, this is the first analysis on the preferences of people with DM in Spain, including a high number of attributes, with the aim of considering all the possible characteristics that should be considered when choosing a treatment for this disease. One of the strengths of this project has been including all possible characteristics associated with current treatments for managing DM that could 
influence patient preferences. The methodology for assessing preferences recommends that the number of attributes be less or equal to 5 [48] to simplify the questionnaire and help participants complete it. However, when considering this conservative scenario with 18 choice attributes, it is necessary to consider the introduction of possible participant bias, as they only focus on the attributes most important to them at the moment of choosing the treatment. This could explain the opposite sign obtained for the $\beta$ coefficient for the attribute of genitourinary infections, since it is possible that the participants felt it more important to consider other attributes, such as HBP, risk of hypoglycaemia or the reduction of $\mathrm{HbA}_{1 \mathrm{c}}$ level, than the increased risk of genitourinary infections, or they might not have suffered these infections.

On the other hand, this project has several limitations that must be considered when interpreting the results. The clinical information including the current treatment or $\mathrm{HbA}_{1 \mathrm{c}}$ level was reported directly by the participants, without confirmation from a physician. The participants with DM may have had a higher degree of adherence and motivation than the general population due to two selection factors: they were members of an association of people with DM (FEDE), and they voluntarily agreed to complete the questionnaire. The $\mathrm{HbA}_{1 \mathrm{c}}$ levels reported by the participants differ from those expected from patients with DM undergoing complex treatments (more than half of the participants used insulin) or with advanced diabetes in Spain [49]. This could indicate that this is a particularly motivated population. Additionally, participants choose between hypothetical treatments, but differences may arise between the stated and the real treatment options. In reference to the sample size, the authors planned this project as an exploratory study because of the lack of evidence in the included population about the basal parameters. The authors assumed that the sample size could show statistical significance $(p<0.05)$ in the model and estimate the coefficients as is shown in Table 2 . We could fail in type II error in the results of cardiovascular improvement $(p=0.051)$ and need for prior authorization $(p=0.091)$, which could reach statistical significance with larger sample size. Therefore, future research is needed to determine whether patient preferences have an impact on outcomes. In addition, patients should be incorporated into the process of designing diabetes protocols and guidelines, thus considering patient preferences in shared decision-making models.

\section{CONCLUSION}

The results of this analysis suggest that people with DM prefer a treatment that generates benefits in those controllable parameters with short-/medium-term consequences, such as reducing blood pressure, while not risking hypoglycaemia, reducing $\mathrm{HbA}_{1 \mathrm{c}}$ level as well as a convenient route of administration. Therefore, given the wide range of therapeutic options, it is important to consider patients' preferences in shared decision-making models, especially in chronic pathologies such as DM. In this way, patients can begin a treatment suited to their expectations, so they will have greater therapeutic adherence and thus better clinical results, reducing morbidity, mortality and disease burden and improving their quality of life.

\section{ACKNOWLEDGEMENTS}

Funding. This study and the Journal's Rapid Service Fee was funded by Novo Nordisk Spain.

Authorship. All named authors meet the International Committee of Medical Journal Editors (ICMJE) criteria for authorship for this article, take responsibility for the integrity of the work as a whole, and have given their approval for this version to be published.

Author Contributions. Álvaro Muñoz, María Mareque and Miguel Ángel Casado proposed the design of the discrete choice experiment. Fernando Gómez-Peralta and Mercedes Maderuelo validated the questionnaire design and the attributes and levels to be included in the questionnaire. All authors have participated 
in the writing of the manuscript in the draft and revision phases and have read and approved the final manuscript.

Disclosures. Fernando Gómez-Peralta has acted as an advisor for Abbott Diabetes, AstraZeneca, Novartis, Novo Nordisk and Sanofi; has been an investigator in clinical trials for Boehringer Ingelheim, Eli Lilly, Novo Nordisk and Sanofi; and has acted as a speaker for Abbott Diabetes, AstraZeneca, Boehringer Ingelheim, Bristol-Myers Squibb, Eli Lilly, Novartis, Novo Nordisk and Sanofi. Mercedes Maderuelo has received honoraria from Novo Nordisk for advocacy tasks related to this project. Miguel Ángel Casado, María Mareque and Álvaro Muñoz are currently employed at PORIB, a consultant company specialized in economic evaluation of health interventions, which received financial support from Novo Nordisk for the development of this study.

Compliance with Ethics Guidelines. Ethical approval is considered unnecessary according to national regulations, as this is not a study but an opinion survey using the discrete choice experiment method. Therefore, as it is not a study, informed consent does not apply.

Data Availability. The datasets generated during and/or analyzed during the current study are available from the corresponding author upon reasonable request and with permission of Novo Nordisk Spain.

Open Access. This article is licensed under a Creative Commons Attribution-NonCommercial 4.0 International License, which permits any non-commercial use, sharing, adaptation, distribution and reproduction in any medium or format, as long as you give appropriate credit to the original author(s) and the source, provide a link to the Creative Commons licence, and indicate if changes were made. The images or other third party material in this article are included in the article's Creative Commons licence, unless indicated otherwise in a credit line to the material. If material is not included in the article's Creative Commons licence and your intended use is not permitted by statutory regulation or exceeds the permitted use, you will need to obtain permission directly from the copyright holder. To view a copy of this licence, visit http:// creativecommons.org/licenses/by-nc/4.0/.

\section{REFERENCES}

1. World Health Organization. World report on diabetes. World Health Organization; 2016 [Acessed 2020 Dic]. https://apps.who.int/iris/handle/10665/ 254649 .

2. International Diabetes Federation (IDF). The Diabetes Atlas, 9th ed, 2019. [Accessed 2020 Dic] Available at: https://diabetesatlas.org/upload/ resources/material/20200302_133352_2406-IDFATLAS-SPAN-BOOK.pdf.

3. Soriguer F, Goday A, Bosch-Comas A, Bordiú E, Calle-Pascual A, Carmena R, et al. Prevalence of diabetes mellitus and impaired glucose regulation in Spain: the Di@bet.es Study. Diabetologia. 2012;55:88-93.

4. Vila L, Viguera J, Alemán R. Diabetic retinopathy and blindness in Spain: epidemiology and prevention. Endocrinol Nutr. 2008;55(10):459-75.

5. Orozco-Beltrán D, Sánchez E, Garrido A, Quesada JA, Carratalá-Munuera MC, Gil-Guillén VF. Trends in mortality from diabetes mellitus in Spain: 1998-2013. Rev Esp Cardiol (Engl Ed). 2017;70(6): $433-43$.

6. Young-Hyman D, de Groot M, Hill-Briggs F, Gonzalez JS, Hood K, Peyrot M. Psychosocial care for people with diabetes: a position statement of the American Diabetes Association. Diabetes Care. 2016;39(12):2126-40.

7. Vileikyte L, Peyrot M, Gonzalez JS, Rubin RR, Garrow AP, Stickings D, Waterman C, Ulbrecht JS, Cavanagh PR, Boulton AJ. Predictors of depressive symptoms in persons with diabetic peripheral neuropathy: a longitudinal study. Diabetologia. 2009;52(7):1265-73.

8. Mata-Cases M, Franch-Nadal J, Real J, Vlacho B, Gómez-García A, Mauricio D. Evaluation of clinical and antidiabetic treatment characteristics of different sub-groups of patients with type 2 diabetes: data from a Mediterranean population database. Prim Care Diabetes. 2021;15(3):588-95. 
9. Cramer JA. A systematic review of adherence with medications for diabetes. Diabetes Care. 2004;27(5): 1218-24.

10. Buysman EK, Liu F, Hammer M, Langer J. Impact of medication adherence and persistence on clinical and economic outcomes in patients with type 2 diabetes treated with liraglutide: a retrospective cohort study. Adv Ther. 2015;32:341-55.

11. López-Simarro F, Brotons C, Moral I, Cols-Sagarra C, Selva A, Aguado-Jodar A. Inercia y cumplimiento terapéutico en pacientes con diabetes mellitus tipo 2 en atención primaria. Med Clin (Barc). 2012;138: 377-84.

12. González-Clemente JM, Font B, Lahoz R, Llauradó G, Gambús G. Grupo de investigadores del Estudio INERCIA Inercia clínica en pacientes con diabetes mellitus tipo 2 no insulinizados en tratamiento con hypoglucemiantes orales. Estudio INERCIA. Med Clin (Barc). 2014;142:478-84.

13. Márquez CE, Martell CN, Gil GV, Casado Martínez JJ, Martin de Pablos JL, Ferraro GJ. El cumplimiento terapéutico con insulina en el tratamiento de la diabetes mellitus tipo 2: estudio CUMINDIAB. Aten Primaria. 2012;44:74-81.

14. Carratalá-Munuera MC, Gil-Guillen VF, OrozcoBeltrán D, Navarro-Pérez J, Caballero-Martínez F, Álvarez-Guisasola F. Barriers associated with poor control in Spanish diabetic patients. A consensus study. Int J Clin Pract. 2013;67:888-94.

15. Farr AM, Sheehan JJ, Curkendall SM, Smith DM, Johnston SS, Kalsekar I. Retrospective analysis of long-term adherence to and persistence with DPP-4 inhibitors in US adults with type 2 diabetes mellitus. Adv Ther. 2014;31:1287-305.

16. Elwyn G, Cochran N, Pignone M. Shared decision making-the importance of diagnosing preferences. JAMA Intern Med. 2017;177(9):1239-40.

17. Asche C, LaFleur J, Conner C. A review of diabetes treatment adherence and the association with clinical and economic outcomes. Clin Ther. 2011;33:74-109.

18. Khunti K, Seidu S, Kunutsor S, Davies M. Association between adherence to pharmacotherapy and outcomes in type 2 diabetes: a meta-analysis. Diabetes Care. 2017;40(11):1588-96.

19. Gómez Peralta F, Luis-Yagüe JR, del Barrio J, París F, Álvarez P, Restovic G. Análisis del impacto económico de la mejora de la adherencia en pacientes con diabetes mellitus tipo 2. Gac Sanit. 2017;31(Espec Congr):391.
20. Buse JB, Wexler DJ, Tsapas A, Rossing P, Mingrone G, Mathieu C, D'Alessio DA, Davies MJ. 2019 Update to: management of hyperglycaemia in type 2 diabetes, 2018. A Consensus Report by the American Diabetes Association (ADA) and the European Association for the Study of Diabetes (EASD). Diabetes Care. 2020;43(2):487-93.

21. Gomez-Peralta F, Escalada San Martín FJ, Menéndez Torre E, Mata Cases M, Ferrer García JC, Ezkurra Loiola P, Ávila Lachica L, Fornos Pérez JA, Artola Menéndez S, Álvarez-Guisasola F, Rica Echevarría I, Girbés Borrás J. Spanish Diabetes Society (SED) recommendations for the pharmacologic treatment of hyperglycaemia in type 2 diabetes: 2018 Update. Endocrinol Diabetes Nutr. 2018;65(10):611-24.

22. Ryan M, Gerard K. Using discrete choice experiments to value health care programmes: current practice and future research reflections. Appl Health Econ Health Policy. 2003;2(1):55-64.

23. de Bekker-Grob EW, Swait JD, Kassahun HT, Bliemer MCJ, Jonker MF, Veldwijk J, Cong K, Rose JM, Donkers B. Are healthcare choices predictable? The impact of discrete choice experiment designs and models. Value Health. 2019;22(9):1050-62.

24. Lancsar E, Fiebig DG, Hole AR. Discrete choice experiments: a guide to model specification, estimation and software. Pharmacoeconomics. 2017;35(7):697-716.

25. de Bekker-Grob EW, Donkers B, Jonker MF, Stolk EA. Sample size requirements for discrete-choice experiments in healthcare: a practical guide. Patient. 2015;8(5):373-84.

26. Joosten EA, DeFuentes-Merillas L, de Weert GH, Sensky T, van der Staak CP, de Jong CA. Systematic review of the effects of shared decision-making on patient satisfaction, treatment adherence and health status. Psychother Psychosom. 2008;77(4): 219-26.

27. Saheb Kashaf M, McGill ET, Berger ZD. Shared decision-making and outcomes in type 2 diabetes: a systematic review and meta-analysis. Patient Educ Couns. 2017;100(12):2159-71.

28. Hughes TM, Merath K, Chen Q, Sun S, Palmer E, Idrees JJ, Okunrintemi V, Squires M, Beal EW, Pawlik TM. Association of shared decision-making on patient-reported health outcomes and healthcare utilization. Am J Surg. 2018;216(1):7-12.

29. Delamater AM. Improving patient adherence. Clin Diabetes. 2006;24(2):71-7.

30. Bridges JFP, Hauber AB, Marshall D, et al. Conjoint analysis applications in health—a checklist: a report 
of the ISPOR good research practices for conjoint analysis task force. Value Health. 2011;14:403-13.

31. Reed Johnson F, Lancsar E, Marshall D, et al. Constructing experimental designs for discrete-choice experiments: report of the ISPOR Conjoint Analysis Experimental Design Good Research Practices Task Force. Value Health. 2013;16:3-13.

32. R Core Team. R: a language and environment for statistical computing. Vienna: R Foundation for Statistical Computing; 2014. http://www.R-project. org. Accessed 2020 Sept.

33. Ozdemir S, Baid D, Verghese NR, Lam AY, Lee PC, Lim AY, Zhu L, Ganguly S, Finkelstein EA, Goh SY. Patient preferences for medications in managing type 2 diabetes mellitus: a discrete choice experiment. Value Health. 2020;23(7):842-50.

34. Donnan JR, Johnston K, Chibrikov E, Marra CA, Aubrey-Bassler K, Najafzadeh M, Nguyen H, Gamble JM. Capturing adult patient preferences toward benefits and risks of second-line antihyperglycemic medications used in type 2 diabetes: a discrete choice experiment. Can J Diabetes. 2020;44(1): 6-13.

35. Khangura D, Kurukulasuriya LR, Whaley-Connell A, Sowers JR. Diabetes and hypertension: clinical update. Am J Hypertens. 2018;31(5):515-21.

36. Grossman A, Grossman E. Blood pressure control in type 2 diabetic patients. Cardiovasc Diabetol. 2017;16(1):3.

37. Sowers JR, Epstein M, Frohlich ED. Diabetes, hypertension, and cardiovascular disease. Hypertension. 2001;37:1053-9.

38. Sowers JR. Recommendations for special populations: diabetes mellitus and the metabolic syndrome. Am J Hypertens. 2003;16(11 Pt 2):41S-45S.

39. Ferrannini G, Norhammar A, Gyberg V, Mellbin L, Rydén L. Is Coronary artery disease inevitable in type 2 diabetes? From a glucocentric to a holistic view on patient management. Diabetes Care. 2020;43(9):2001-9.

40. Schoenborn NL, Crossnohere NL, Bridges JFP, Pollack CE, Pilla SJ, Boyd CM. Patient perceptions of diabetes guideline frameworks for individualizing glycaemic targets. JAMA Intern Med. 2019;179(12): 1642-9.

41. Kruger DF, LaRue S, Estepa P. Recognition of and steps to mitigate anxiety and fear of pain in injectable diabetes treatment. Diabetes Metab Syndr Obes. 2015;8:49-56.

42. Kruger DF, LaRue S, Estepa P. Recognition of and steps to mitigate anxiety and fear of pain in injectable diabetes treatment. Diabetes Metab Syndr Obes. 2015;8:49-56.

43. Cemeroglu AP, Can A, Davis AT, Cemeroglu O, Kleis L, Daniel MS, Bustraan J, Koehler TJ. Fear of needles in children with type 1 diabetes mellitus on multiple daily injections and continuous subcutaneous insulin infusion. Endocr Pract. 2015;21(1): 46-53.

44. Rex J, Jensen KH, Lawton SA. A review of 20 years' experience with the NovoPen family of insulin injection devices. Clin Drug Investig. 2006;26(7): 367-401.

45. Osterberg L, Blaschke T. Adherence to medication. N Engl J Med. 2005;353(5):487-97.

46. Fundación redGDPS. Guía de diabetes tipo 2 para clínicos: Recomendaciones de la redGDPS. 2018. Available at: https://www.redgdps.org/gestor/ upload/colecciones/Guia\%20DM2_web.pdf. Accessed 2020 Dec.

47. Von Arx LB, Kjeer T. The patient perspective of diabetes care: a systematic review of stated preference research. Patient. 2014;7(3):283-300.

48. York Health Economics Consortium. Discrete Choice Experiment (DCE) [online]; 2016. Available at: https:// yhec.co.uk/glossary/discrete-choice-experi ment-dce/. Accessed 2020 Dec.

49. Pérez A, Franch J, Cases A, González Juanatey JR, Conthe P, Gimeno E, Matali A. Relación del grado de control glucémico con las características de la diabetes y el tratamiento de la hiperglucemia en la diabetes tipo 2. Estudio DIABES Med Clin (Barc). 2012;138(12):505-11. 